\title{
BMJ Open Changes in quality of life 5 years after sleeve gastrectomy: a prospective cohort study
}

\author{
Tone Nygaard Flølo, ${ }^{1,2}$ Grethe S Tell, ${ }^{2}$ Ronette L Kolotkin, ${ }^{3,4,5,6}$ Anny Aasprang, ${ }^{3,4}$ \\ Tone Merete Norekvål, ${ }^{\oplus 3,7,8}$ Villy Våge, ${ }^{9,10}$ Karl Ove Hufthammer, ${ }^{\oplus} 11$ \\ John Roger Andersen ${ }^{3,4}$
}

To cite: Flølo TN, Tell GS, Kolotkin RL, et al. Changes in quality of life 5 years after sleeve gastrectomy: a prospective cohort study. BMJ Open 2019;9:e031170. doi:10.1136/ bmjopen-2019-031170

- Prepublication history for this paper is available online. To view these files, please visit the journal online (http://dx.doi. org/10.1136/bmjopen-2019031170).

Received 19 April 2019 Revised 12 July 2019 Accepted 23 August 2019

Check for updates

(c) Author(s) (or their employer(s)) 2019. Re-use permitted under CC BY-NC. No commercial re-use. See rights and permissions. Published by BMJ.

For numbered affiliations see end of article.

Correspondence to Tone Nygaard Flølo; tone.flolo@helse-bergen.no

\section{ABSTRACT}

Objectives Sleeve gastrectomy (SG) is the most frequently performed bariatric surgery procedure worldwide, but reports on long-term quality of life (QOL) outcomes are scarce. We investigated 5-year trajectories in QOL and their associations with weight loss after SG.

Design A prospective cohort study.

Setting The study was conducted in a single Norwegian bariatric surgery centre.

Participants Out of 150 operated patients, 127 were included. Mean age was 41 years, $68 \%$ were women and the follow-up rate at 1 year was $85 \%$ and $64 \%$ at 1 and 5 years, respectively.

Outcome measures Data were collected preoperatively, and 1 and 5 years after surgery assessing three different levels of QOL. The main exposure was weight loss after $\mathrm{SG}$, assessed as per cent excess body mass index $\left(\mathrm{kg} / \mathrm{m}^{2}\right)$ Ioss (\%EBMIL). The Obesity-Related Problem (OP) scale was used to measure obesity-specific health-related QOL (HRQOL). Physical (PCS) and mental (MCS) composite summary scores of the Short Form 36 Health Survey were used to capture generic HRQOL and Cantril Ladder was used to assess overall QOL.

Results All HRQOL/overall QOL measures significantly improved at 1 year, followed by modest decline from 1 to 5 years after surgery. Greater \%EBMIL 5 years after surgery was significantly associated with improvements in OP and PCS scores, but not with MCS and Cantril Ladder scores. Although significant $(p<0.001)$ and clinically relevant improvements in HRQOL/overall QOL outcomes were observed at 5 years, scores were still below the general population norms.

Conclusion Most patients undergoing SG experience substantial weight loss accompanied by statistically significant and clinically relevant long-term improvements in HRQOL/overall QOL. However, an important minority of patients still report low HRQOL/overall QOL 5 years after SG. Further research should aim to identify other factors that contribute to impaired QOL after bariatric surgery, even in the presence of successful weight control.

\section{INTRODUCTION}

Impaired quality of life (QOL) is a strong incentive for individuals with severe obesity to seek help for their condition. Thus, QOL is considered a main measure of treatment

\section{Strengths and limitations of this study}

- This prospective 5-year study expands the limited knowledge of long-term quality of life outcomes and their association with weight loss after sleeve gastrectomy for severe obesity.

- By applying obesity-specific, generic and overall quality of life outcome measures, the impact of weight loss following sleeve gastrectomy on diverse life domains is assessed broadly.

- All long-term quality of life outcomes are compared with general population norms.

- The proportion of patients lost to follow-up at 5 years is a limitation.

efficacy after bariatric surgery. ${ }^{1-4}$ The broad concept of QOL encompasses overall, generic and disease-specific QOL domains.

Sleeve gastrectomy (SG) is now the most frequently performed bariatric surgery procedure worldwide, and keeping the intestines intact is regarded as a main advantage compared with other surgical methods. ${ }^{5}$ Although associated with substantial short (1 year) and medium-term (2-3years) improvements in a range of patient-reported outcomes, long-term ( $\geq 5$ years) reports on QOL after SG are scarce. ${ }^{6-8}$

To the best of our knowledge, only one publication reports prospective long-term QOL data after $\mathrm{SG} .{ }^{9}$ In a single-centre study, the obesity-specific Moorehead-Ardelt II (MAII) questionnaire and a visual analogue scale to represent overall QOL were used. The authors reported improvements in QOL until 2 years, followed by subsequent declines from 2 to 5 years after SG. Weight loss was not associated with either obesity-specific or overall QOL. The absence of a generic questionnaire precluded comparisons with QOL in the general population. Cross-sectional reports on generic QOL using the Short Form 36 Health Survey (SF-36) 5 years after 
SG are published. ${ }^{10-12}$ Comparing two similar cohorts of patients before and 5 years after surgery, we reported that mean SF-36 scores were significantly higher in the 5-year cohort than in the baseline cohort, although still below the general population norm. ${ }^{12}$ However, firm conclusions on improvements in QOL cannot be drawn from cross-sectional studies alone and should rely on more than solely generic QOL measures.

Thus, the aim of this prospective study was to investigate long-term trajectories in QOL following SG, and to compare long-term QOL scores to those from the general population. To avoid conceptual ambiguity, the broad term QOL was divided into three levels: (1) overall QOL representing satisfaction with life as a whole, (2) generic health-related QOL (HRQOL) representing broad domains of physical and mental health, and (3) obesity-specific HRQOL representing patients' perception of QOL specifically related to their weight. ${ }^{13}$ Furthermore, we aimed to investigate associations between long-term weight loss and QOL at all three levels.

\section{METHODS \\ Patients}

The eligibility criteria for SG were a body mass index (BMI) $\geq 40 \mathrm{~kg} / \mathrm{m}^{2}$, or $\geq 35 \mathrm{~kg} / \mathrm{m}^{2}$ with obesity-related comorbidities, age from 18 to 65 years and absence of active psychosis, alcohol or drug abuse. All eligible patients who underwent SG from January 2010 to December 2013 at a single bariatric centre were recruited. Written informed consent was obtained at the preoperative outpatient visit. Preoperative evaluation and follow-up were routinely performed by a multidisciplinary team including the surgeon, a dietitian and a nurse 3 months before surgery, and 3, 12, 24 and 60 months postoperatively. Other healthcare professionals, such as a physiotherapist or psychologist were consulted as needed. Data were collected preoperatively, and during follow-up consultations 1 and 5 years after surgery.

\section{Patient and public involvement}

In line with requirements from the public funder of this research, patient involvement was ensured by discussing the initial study protocol with the national support group for people with overweight and obesity. The results will be disseminated to the study participants via newsletters and social media platforms after the study results are published.

\section{The treatment: Sleeve gastrectomy}

Two surgeons performed the SG operations using a 32 French tube as template for the resection, starting $1-2 \mathrm{~cm}$ proximal to the pylorus and ending at the cardia. The standardised technical procedure has been previously described. ${ }^{12} 14$

\section{Demographics and clinical variables}

Information on patients' age, sex, marital/cohabitation status and educational level was recorded. Body weight was measured in light clothing without shoes to the nearest $0.1 \mathrm{~kg}$, while height was measured in a standing position without shoes to the nearest $0.01 \mathrm{~m}$. BMI was calculated as weight divided by height squared $\left(\mathrm{kg} / \mathrm{m}^{2}\right)$. Weight loss is presented as change in BMI $(\triangle \mathrm{BMI}=$ initial BMI-postoperative BMI) and per cent excess BMI loss $(\% \mathrm{EBMIL}=\Delta \mathrm{BMI} /($ initial BMI-25 $) \times 100) .{ }^{15} \mathrm{We}$ also report number of patients with more than $10 \mathrm{~kg}$ weight regain between 1 and 5 years ${ }^{16}$ and number of patients whose \% EBMIL was below 50 at 5 years. ${ }^{17}$ Furthermore, we report number of patients whose BMI was below $30 \mathrm{~kg} / \mathrm{m}^{2} 5$ years after SG. ${ }^{18}$

\section{Obesity-specific HRQOL}

The Obesity-Related Problem (OP) scale, which captures obesity-specific psychosocial functioning in various daily life situations, was used to measure obesity-specific HRQOL. The questionnaire comprises eight items regarding (1) parties/social gatherings at home; (2) parties/social gatherings at a friend's place; (3) going to restaurants; (4) participating in organisations, attending courses, and so on; (5) going on vacations; (6) trying on and buying clothes; (7) bathing in public areas (swimming pools, beaches); and (8) sexual intercourse, intimate relations with partner. Patients' statements range from 0 to 3 : 'definitely not bothered' $(0)$, 'not so bothered' (1), 'mostly bothered' (2) and 'definitely bothered' (3). The summary raw total score is transformed to a standardised scale from 0 to 100 , in which lower scores refer to higher degrees of psychosocial functioning. Scores below 20 indicate no or mild psychosocial impairment, from 20 to $<40$ mild impairment, from 40 to $<60$ moderate impairment, from 60 to $<80$ severe impairment and $\geq 80$

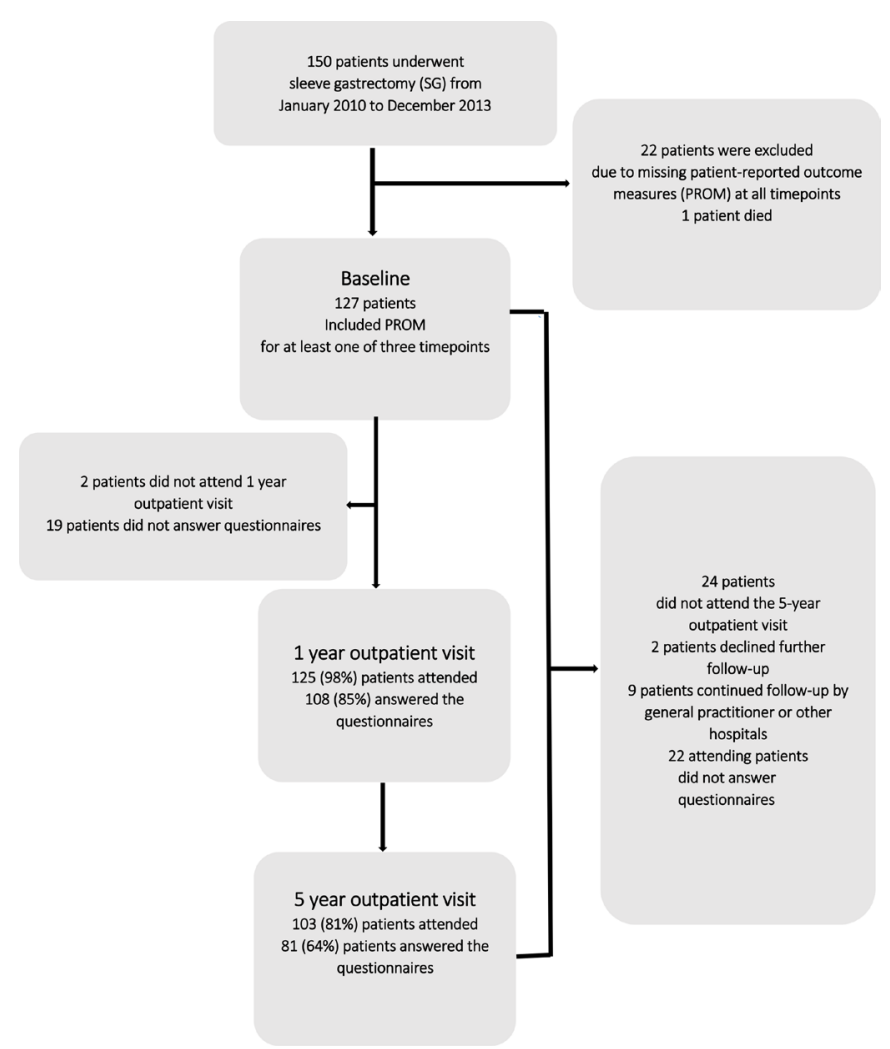

Figure 1 Patient flow chart from recruitment to 5-year follow-up. 
Table 1 Preoperative characteristics in patients with follow-up data at 5 years compared with patients lost to follow-up

\begin{tabular}{|c|c|c|c|c|}
\hline & All patients $n=127$ & $\begin{array}{l}\text { Available at follow-up } \\
\text { (5years) } n=81(64 \%)\end{array}$ & $\begin{array}{l}\text { Lost to follow-up ( } 5 \\
\text { years) } n=46(36 \%)\end{array}$ & $\begin{array}{l}\text { Difference } \\
\text { ( } \mathrm{P} \text { value) }\end{array}$ \\
\hline Age (years) & $41.4 \pm 12.6$ & $41.0 \pm 12.5$ & $42.2 \pm 12.9$ & 0.589 \\
\hline Women, n (\%) & $86 / 127(68 \%)$ & $55 / 81(67.9 \%)$ & $31 / 46(77.4 \%)$ & 0.953 \\
\hline $\mathrm{BMI}\left(\mathrm{kg} / \mathrm{m}^{2}\right.$, mean $\left.\pm \mathrm{SD}\right)$ & $44.8 \pm 6.0$ & $44.2 \pm 2.9$ & $46.0 \pm 6.1$ & 0.113 \\
\hline Superobese $\left(\mathrm{BMI} \geq 50 \mathrm{~kg} / \mathrm{m}^{2}\right)$ & $22 / 127$ (17.3\%) & $12 / 81(14.8 \%)$ & $10 / 46(21.7 \%)$ & 0.322 \\
\hline Married/cohabitants, n (\%) & $74 / 127(58.7 \%)$ & $48 / 81(59.3 \%)$ & $26 / 45(57.8 \%)$ & 0.851 \\
\hline Higher education, $\mathrm{n}(\%)^{\star}$ & $32 / 125(25.6 \%)$ & 19/81 (23.4\%) & $13 / 44(29.5 \%)$ & 0.322 \\
\hline Anxiety (medically treated), $n(\%)$ & $13 / 126(10.3 \%)$ & $7 / 80(8.8 \%)$ & $6 / 46(13.0 \%)$ & 0.446 \\
\hline $\begin{array}{l}\text { Depression (medically treated), } \mathrm{n} \\
\text { (\%) }\end{array}$ & $24 / 127$ (18.9\%) & $15 / 81(18.5 \%)$ & 9/46 (19.6\%) & 0.855 \\
\hline OP total $($ mean $\pm S D)$ & $63.2 \pm 24.6$ & $62.7 \pm 25.3$ & $64.0 \pm 23.6$ & 0.421 \\
\hline MCS (mean $\pm S D)$ & $42.9 \pm 10.8$ & $43.0 \pm 10.8$ & $42.6 \pm 11.0$ & 0.458 \\
\hline PCS (mean \pm SD) & $38.4 \pm 8.8$ & $39.0 \pm 8.7$ & $37.3 \pm 9.0$ & 0.458 \\
\hline Cantril's Ladder (mean $\pm S D)$ & $4.9 \pm 1.8$ & $5.0 \pm 1.8$ & $4.8 \pm 1.8$ & 0.697 \\
\hline
\end{tabular}

${ }^{*}$ Higher education $=\geq 3$ years at university/college. $\chi^{2}$ test was performed for comparing categorical variables. Independent $t$-test was performed for comparing continuous variables. Differences were considered statistically significant if $p \leq 0.05$.

BMI, body mass index;Cantril's Ladder, overall quality of life; MCS, mental composite summary score; OP total, Obesity-Related Problem scale total score; PCS, physical composite summary score.

extreme impairment. ${ }^{19}$ In addition to the OP total score, we report responses to the eight individual items. The OP has been translated and validated for Norwegian bariatric patients. ${ }^{20}$

\section{Generic HRQOL}

The SF-36 was used to measure generic HRQOL. This is a widely used HRQOL instrument, also recommended as the generic measure of choice in obesity research. ${ }^{21}{ }^{22}$ It contains 36 items with eight subscales regarding (1) physical functioning, (2) physical role, (3) bodily pain, (4) general health, (5) vitality, (6) social functioning, (7) emotional role functioning, and (8) mental health. ${ }^{23}$ Herein we use the two SF-36 summary scores based on factor analysis with oblique rotation; that is, physical composite summary (PCS) and mental composite summary (MCS). The PCS and MCS cluster the eight subscales according to common physical and mental attributions. Each of the two summary components is assessed on a transformed scale where higher scores represent better physical or mental HRQOL. ${ }^{23}$ The SF-36 is psychometrically validated for use in Norwegian patients with severe obesity. ${ }^{24}$

\section{Overall QOL}

Cantril Ladder, containing one item, has been widely used in various populations and in different settings and is considered a valid and reliable measure of overall QOL. ${ }^{20}{ }^{25}{ }^{26}$ Respondents were asked to think of a ladder numbered from 0 to 10 , with the best possible life being 10 , and the worst possible life being 0 . They were then asked to rate the perception of their own current lives on one of the steps between 0 and 10. A score of 6 or more is labelled 'high life satisfaction' and less than 6 'low life satisfaction'.
General population scores on HRQOL and overall QOL

For comparison, HRQOL and overall QOL values representing the general population were obtained from three different data sets. Population scores on the OP scale were derived from a randomly selected Swedish sample $(\mathrm{n}=1.017)$ with a $\mathrm{BMI}<30 .{ }^{27}$ Population scores on SF-36 $(n=5.396)^{28}$ and data representing Cantril Ladder $(\mathrm{n}=6.129)^{29}$ were derived from two randomly selected Norwegian samples including all BMI categories.

\section{Statistical analyses}

Continuous variables are presented as means $\pm \mathrm{SD}$ or $95 \%$ CIs. Categorical variables are presented as counts and percentages (\%). Available patients at 5-year follow-up and patients lost to follow-up were compared for baseline differences.

An a priori power calculation was performed based on previous changes observed in HRQOL from baseline to 5 years after biliopancreatic diversion with duodenal switch (BPDDS) surgery. ${ }^{30}$ With an expected $\mathrm{n}=120$, power $=90 \%$ and $\mathrm{p}=0.05$ we could discover a statistically significant change equal to $0.30 \mathrm{SD}$ (two-sided paired t-test). Expected change was $>0.76 \mathrm{SD}$.

The BMI values, OP scale, QOL, SF-36 MCS and SF-36 PCS scores were all modelled using longitudinal regression models with time as a (categorical) explanatory variable, a hetereoscedastic error structure (different variances at each time point) and an unstructured correlation matrix. These models use data from all patients, even patients with partially missing data, reducing potential bias introduced by non-random loss to follow-up. The models were fitted using generalised least squares by the 'nlme' R package. ${ }^{31}$ For testing changes in single OP 
items, we used paired t-tests, not adjusted for multiple comparisons.

To assess whether the OP total score, SF-36 (MCS and PCS) and Cantril Ladder at 5 years were associated with $\%$ EBMIL from baseline to 5 years, or could be predicted by baseline variables, we fitted four unadjusted and adjusted linear regression models. The following covariates were included: age, sex, baseline BMI, the corresponding baseline HRQOL/overall QOL score of the dependent variable and \%EBMIL from baseline to 5 years.

For handling missing data, we used multiple imputation (200 imputations), based on predictive mean matching. This was done with the 'aregImpute()' function in the 'rms' R package ${ }^{32}$ with default arguments. The variables used in the imputation models were the ones included in the regression models.

Population norms for SF-36 and Cantril Ladder were adjusted by age and gender to reflect the same distribution as in our study sample. The method for this adjustment has been described elsewhere ${ }^{33}$ For the OP score, the published average non-obese population score was used; $58 \%$ were women and age ranged from 37 to 61 years. ${ }^{19}$ The one-sample t-test was used to compare the study sample with the population norms.

Clinical relevance of changes in patient-reported outcomes over time was defined by calculating the mean difference in HRQOL/overall QOL between two time points divided by the pooled SD, using Cohen's $d$ for effect size (ES) ([M2-M1]/SD baseline). These ES were judged according to general criteria: trivial $(<0.2)$, small $(0.2$ to $<0.5)$, moderate $(0.5$ to $<0.8)$ and large $(\geq 0.8){ }^{34}$ Cohen's cut-offs are in accordance with findings from a range of study populations suggesting that a difference of $0.5 \mathrm{SD}$ in HRQOL outcomes, either at individual or at group level, most likely is clinically relevant. Smaller ES may also be important. ${ }^{35}$ Hence, these criteria also guided the assessments of clinically relevant differences in HRQOL/overall QOL between the present cohort at 5 years and population norms.

Statistical significance was set to $p \leq 0.05$. Analyses were performed using R V.3.5.1 $1^{36}$ and Statistical Package for Social Sciences for Windows, V.23.0 (SPSS).

The Strengthening the Reporting of Observational Studies in Epidemiology cohort reporting checklist was used according to BMJ open's author guidelines. ${ }^{37}$

\section{RESULTS}

\section{Sample characteristics}

During the recruitment period, 150 patients underwent SG. Twenty-three patients were later excluded as study participants; 22 because patient-reported data were missing at all time points due to administrative mistakes, and one patient died of reasons unrelated to the SG. Of the 127 included SG patients (mean age $41 \pm 13$ years, $68 \%$ women), complete follow-up data were available for $85 \%$ and $64 \%$ of the patients at 1 and 5 years, respectively (figure 1). No statistically significant differences were seen
Table 2 Comparisons of mean QOL scores/BMI values at baseline, 1 year and 5 years after sleeve gastrectomy $(n=127)^{*}$

\begin{tabular}{|c|c|c|c|c|c|}
\hline & $\mathbf{n}$ & Mean & SD & $95 \% \mathrm{Cl}$ & $\begin{array}{l}\text { Baseline } \\
\text { versus } \\
5 \text { years }\end{array}$ \\
\hline \multicolumn{6}{|l|}{ BMI } \\
\hline Baseline & 127 & 45 & 6 & 44 to 46 & \\
\hline 1 year $†$ & 125 & 30 & 5 & 29 to 31 & \\
\hline 5 years $\ddagger$ & 103 & 32 & 6 & 31 to 33 & \\
\hline \multicolumn{6}{|l|}{ OP } \\
\hline Baseline & 127 & 63 & 25 & 59 to 67 & \\
\hline 1 yeart & 110 & 21 & 21 & 18 to 25 & \\
\hline 5 years $\ddagger$ & 81 & 31 & 28 & 25 to 36 & \\
\hline Effect size & & & & & 1.3 \\
\hline \multicolumn{6}{|l|}{ SF-36 MCS } \\
\hline Baseline & 123 & 43 & 11 & 41 to 45 & \\
\hline 1 year† & 108 & 53 & 9 & 51 to 55 & \\
\hline 5 years $\neq$ & 78 & 48 & 12 & 45 to 50 & \\
\hline Effect size & & & & & 0.3 \\
\hline \multicolumn{6}{|l|}{ SF-36 PCS } \\
\hline Baseline & 123 & 38 & 9 & 37 to 40 & \\
\hline 1 yeart & 108 & 52 & 8 & 51 to 54 & \\
\hline 5 years $\ddagger$ & 78 & 46 & 12 & 44 to 49 & \\
\hline Effect size & & & & & 0.4 \\
\hline \multicolumn{6}{|l|}{$\begin{array}{l}\text { Cantril's } \\
\text { Ladder }\end{array}$} \\
\hline Baseline & 121 & 4.9 & 1.8 & 4.6 to 5.2 & \\
\hline 1 yeart & 109 & 7.4 & 1.6 & 7.1 to 7.7 & \\
\hline 5 years $\ddagger$ & 72 & 6.4 & 1.9 & 5.9 to 6.8 & \\
\hline Effect size & & & & & 0.8 \\
\hline
\end{tabular}

*All estimates, Cls and $p$ values are based on longitudinal models, that is, on the joint distribution of measurements/responses from all three time points (stratified by questionnaire/method).

†All $p$ values for differences in mean scores for 1 and 5 years compared with baseline were $<0.001$.

$\ddagger$ All $p$ values for differences in mean scores for 5 years compared with 1 year were $<0.001$.

BMI, body mass index; MCS, mental composite summary score; OP, Obesity-Related Problem scale; PCS, physical composite summary score; QOL, quality of life; SF-36, Short Form 36 Health Survey.

in preoperative characteristics between patients available and lost to follow-up at 5 years postoperatively (table 1 ).

\section{Change in BMI}

On average, a significant decrease in BMI occurred from baseline to 1 year, followed by a subsequent modest, but statistically significant increase from 1 to 5 years after surgery (table 2). Mean \%EBMIL was 76 (95\% CI 72 to $80)$ and 64 (95\% CI 59 to 70$)$ after 1 and 5 years, respectively, and weight loss corresponding to $\% \mathrm{EBMIL} \geq 50$ was seen in 73/103 $(71 \%)$ patients at 5 years after SG. Highest observed \%EBMIL at 5 years was 125 and the lowest was -18 . Forty of $103(39 \%)$ evaluable patients obtained a 
BMI $<30 \mathrm{~kg} / \mathrm{m}^{2}$ after 5 years, and 38/103 (37\%) patients gained $\geq 10 \mathrm{~kg}$ from 1 to 5 years postoperatively.

\section{Changes in obesity-specific HRQOL}

Significant improvement in mean OP scores occurred from baseline to 1year, followed by a subsequent modest, but statistically significant, decline from 1 to 5 years after surgery (table 2). The improvement in the OP total score from baseline to 5 years was statistically significant with an ES of 1.3.

Preoperatively, $61 \%$ of the patients reported extreme or severe psychosocial impairment in all daily life activities (OP total score $\geq 60$ ). One year after surgery, extreme or severe impairment was reported by $6 \%$ of the patients, and by $16 \%$ after 5 years. Four patients $(5 \%)$ reported higher psychosocial impairment 5 years after SG compared with their preoperative status.

Scores on each of the eight daily life situations covered by the OP largely improved from baseline to 1 year $(\mathrm{p}<0.001)$ (figures 2 and 3 , table 3$)$. From 1 to 5 years, there were small, but significant declines $(\mathrm{p} \leq 0.05)$ for all situations, except for 'bathing in public areas' $(\mathrm{p}=0.58)$ and 'sexual intercourse/intimate situations' $(\mathrm{p}=0.22)$. The greatest improvement was seen for 'trying on and buying clothes', with $67 \%$ of patients reporting this activity to be 'definitely bothersome' preoperatively, compared with $9 \%$ at 5 years postoperatively. Patients who obtained a BMI $<30 \mathrm{~kg} / \mathrm{m}^{2}$ at 5 years after SG reported significantly higher psychosocial functioning (ie, mean OP total) than did patients with a BMI $\geq 30 \mathrm{~kg} / \mathrm{m}^{2}$ (20 vs 35 , mean difference $15,95 \%$ CI 3.8 to $26.1, \mathrm{p}=0.01$ ), yet still significantly below the population norm (mean difference 11.5, 95\% CI 3.7 to $19.4, \mathrm{p}=0.005)$. Mean OP total score at 5 years was 20.6 (95\% CI 14.7 to 26.6 ; $\mathrm{p}<0.001$ ) points higher (ie, poorer psychosocial functioning) in the present cohort than in the population norm. ${ }^{19}$ This difference corresponds to an ES of 0.7.

\section{Changes in generic HRQOL}

Significant improvements on mean PCS and MCS scores occurred from baseline to 1 year, followed by a subsequent modest, but significant decline from 1 to 5 years after surgery (table 2, figure 4). Nevertheless, improvements from baseline to 5 years were statistically significant for both domains with an ES of 0.9 and 0.44 for PCS and MCS, respectively. Mean PCS and MCS scores at 5 years in the present cohort were $4.9(95 \%$ CI 2.3 to 7.6 ; $\mathrm{p}<0.001)$ and $4.2(95 \%$ CI 1.5 to $6.9 ; \mathrm{p}=0.003)$ points lower (ie, poorer), respectively, than in the population norm. ${ }^{28}$ These differences correspond to ES of 0.4 and 0.3 , respectively. Patients who obtained a BMI $<30 \mathrm{~kg} / \mathrm{m}^{2}$ at 5 years after SG reported significantly higher PCS scores than did patients with a BMI $\geq 30 \mathrm{~kg} / \mathrm{m}^{2}$ (50.9 vs 44.1 , mean difference $6.8,95 \%$ CI 1.7 to $12.1, \mathrm{p}=0.01$ ). There was no significant difference in MCS scores in the two groups of patients.

\section{Changes in overall QOL}

Significant improvement in the Cantril Ladder mean score occurred from baseline to 1 year, followed by a subsequent modest, but significant decline from 1 to 5 years after surgery (table 2). The improvement from baseline to 5 years was still statistically significant $(\mathrm{p}<0.001)$ with an ES of 0.8. Low overall QOL (Cantril Ladder score $<6$ ) was reported by $67 \%$ of the patients preoperatively, compared with $13 \%$ and $32 \%$ of the patients at 1 and 5 years after SG, respectively. The mean Cantril Ladder score at 5 years was $1.5(95 \%$ CI 1.1 to $2.0 ; \mathrm{p}<0.001)$ points poorer in the present cohort than the population norm, ${ }^{29}$ equivalent to an ES of 0.8. There was no significant difference in overall QOL at 5 years in patients who obtained a BMI
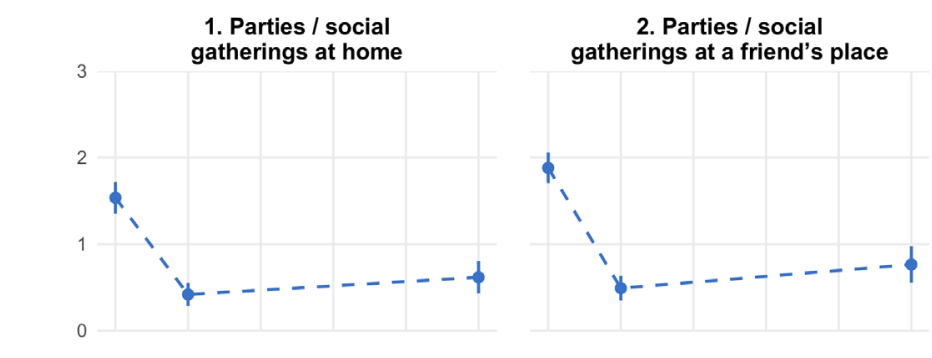

3. Going to restaurants

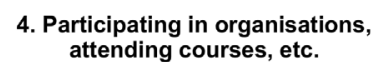

Score

5. Going on vacation
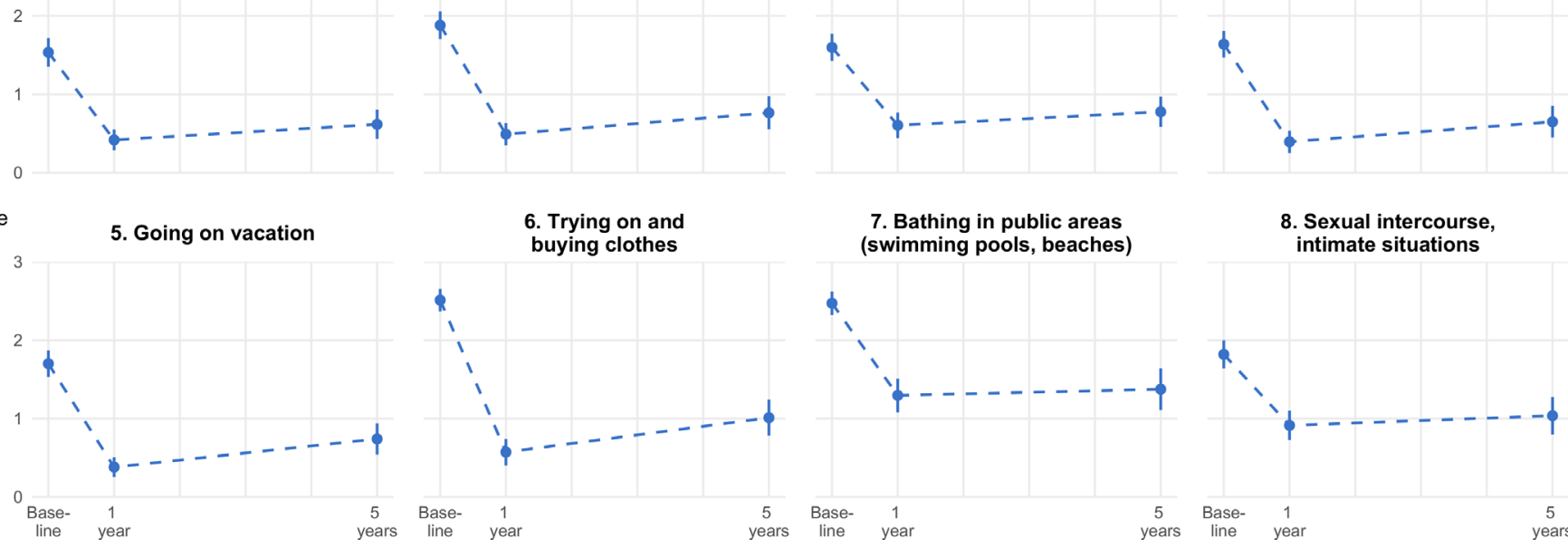

Figure 2 Mean scores with 95\% Cls for the eight Obesity-Related Problem (OP) scale items at baseline, 1 year and 5 years $\left(n=127^{\star}\right)$. ${ }^{*}$ The number of responses differed by time point and questions: $122-127$ at baseline, 105-110 at 1 year and 79-81 at 5 years. 
$<30 \mathrm{~kg} / \mathrm{m}^{2}$ at 5 years after SG compared with patients with a BMI $\geq 30 \mathrm{~kg} / \mathrm{m}^{2}$.

\section{Associations between weight loss and HRQOL/overall QOL}

In the adjusted regression models with OP, MCS, PCS and Cantril Ladder scores at 5 years as dependent variables, the baseline HRQOL/overall QOL variables predicted OP, MCS and PCS, but not Cantril Ladder at 5 years. In addition, baseline BMI predicted OP score, but none of the other HRQOL/overall QOL outcome measures at 5 years. According to the adjusted model, the OP score increases by on average 1.7 points (95\% CI 0.6 to 2.7$)$ for each baseline additional BMI point. The OP total score decreased by on average 29.2 points (95\% CI 8.7 to 49.8 ) for each additional \%EBMIL between baseline and 5 years (table 4). Moreover, \%EBMIL at 5 years was significantly associated with OP and PCS scores, but not with MCS and
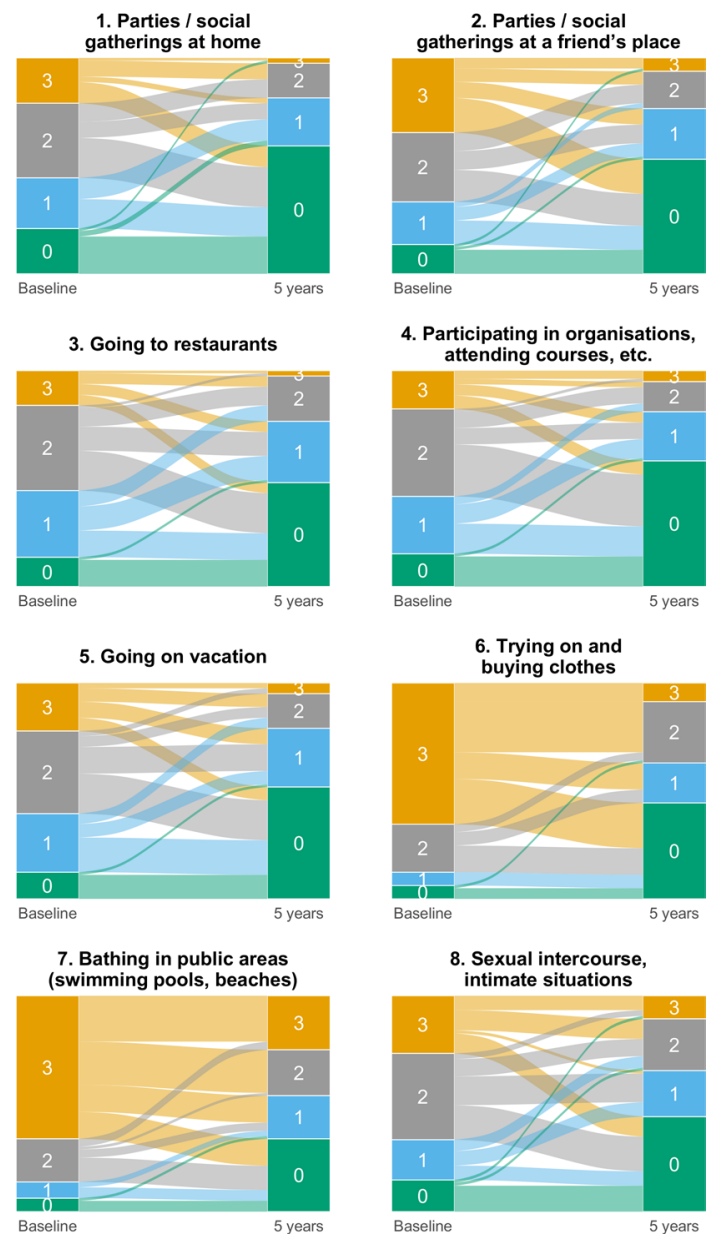

Figure 3 Individual changes in Obesity-Related Problem (OP) items from baseline to 5 years $\left(n=81^{*}\right)$. The response options were 0 ('definitely not bothered'), 1 ('not so bothered'), 2 ('mostly bothered') and 3 ('definitely bothered'). The height of each bar is proportional to the number of patients with the corresponding response, and the width of the ends of each flow line is proportional to the number of patients with the given response pattern. *Only patients who answered the questionnaire at both time points are included, and the number of patients varied between 75 and 81 (depending on the question).
Cantril Ladder after 5 years. The adjusted values for $\mathrm{R}^{2}$, contributed by all variables together, on OP total score and PCS were 0.36 and 0.29 , respectively.

\section{DISCUSSION}

\section{Principal findings and comparisons with other studies}

In this prospective 5-year study of patients undergoing SG, we observed statistically significant and clinically meaningful improvements in all levels of QOL (ie, obesity-specific and generic HRQOL, and overall QOL) from before SG to 5 years after the procedure. In terms of weight loss, the average BMI dropped significantly and markedly during the first year with a subsequent modest regain in BMI occurring at 5 years. A corresponding pattern was seen for all QOL measures demonstrating significant mean improvements at 1 year, followed by a slight decline from 1 to 5 years postoperatively. Adjusted regression analyses showed that preoperative BMI significantly predicted OP score at 5 years, and that \%EBMIL from baseline to 5 years was significantly associated with both OP and PCS scores 5 years after SG. Although significantly improved, mean total scores on both obesity-specific, generic HRQOL and overall QOL outcomes in the current study were below the general population norms 5 years after SG.

The purpose of our study was to expand the limited knowledge on long-term changes in disease-specific and generic HRQOL, as well as overall QOL after SG. To our knowledge, only one study on long-term obesity-specific HRQOL and overall QOL after SG has been published, but the use of different questionnaires hampers direct comparison of HRQOL/overall QOL outcomes. ${ }^{9}$ In the study of Charalampakis $e t a l$, the time-dependent changes in weight and obesity-specific HRQOL/overall QOL were mainly consistent with findings in the current paper. Furthermore, our results on changes in HRQOL are in accordance with previous reports on long-term trajectories following BPDDS and Roux-en-Y gastric bypass (RYGBP) as measured by the OP scale and/or SF-36. ${ }^{22}{ }^{38-41}$ Specifically, Karlsson et al reported changes in OP total score from before to 10 years after RYGBP corresponding to an ES of 1.0, compared with 1.3 in the current study, that is, large clinically relevant improvements. ${ }^{38}$ Aasprang et al reported mean MCS and PCS, as measured by the SF-36, at 5 years after BPDDS nearly identical to the current study, also with small to moderate ES for improvements. ${ }^{40}$ Long-term HRQOL scores were significantly below the population norm in both studies. Furthermore, Kolotkin et al compared HRQOL changes between RYGBP and non-surgery patients at 6 years using the obesity-specific Impact of Weight on Quality of Life-Lite (IWQOL-Lite) questionnaire and SF-36. ${ }^{39}$ For the RYGBP group, large and significant improvements in both obesity-specific and generic HRQOL (PCS only) were seen from baseline to 6 years; nonetheless, PCS scores at 6 years were below US norms and IWQOL-Lite total score was below a non-obese community reference group. Overall, there seem to be 
Table 3 Comparison of mean scores on individual items in the OP scale, at baseline, 1 year and 5 years after sleeve gastrectomy $(n=127)$

\begin{tabular}{|c|c|c|c|c|c|}
\hline & Respondents & Mean & SD & $95 \% \mathrm{Cl}$ & P value* \\
\hline \multicolumn{6}{|c|}{ OP 1: Parties/social gatherings at home } \\
\hline Baseline & 127 & 1.5 & 1.0 & 1.4 to 1.7 & - \\
\hline 1 year & 110 & 0.4 & 0.7 & 0.3 to 0.6 & $<0.001$ \\
\hline 5 years & 81 & 0.6 & 0.8 & 0.4 to 0.8 & 0.01 \\
\hline \multicolumn{6}{|c|}{ OP 2: Parties/social gatherings at a friend's place } \\
\hline Baseline & 127 & 1.9 & 1.0 & 1.7 to 2.1 & - \\
\hline 1 year & 110 & 0.5 & 0.8 & 0.3 to 0.6 & $<0.001$ \\
\hline 5 years & 81 & 0.8 & 1.0 & 0.6 to 1.0 & 0.002 \\
\hline \multicolumn{6}{|c|}{ OP 3: Going to restaurants } \\
\hline Baseline & 127 & 1.6 & 1.0 & 1.4 to 1.8 & - \\
\hline 1 year & 109 & 0.6 & 0.9 & 0.4 to 0.8 & $<0.001$ \\
\hline 5 years & 81 & 0.8 & 0.9 & 0.6 to 1.0 & 0.05 \\
\hline \multicolumn{6}{|c|}{ OP 4: Participating in organisations, attending courses, and so on } \\
\hline Baseline & 125 & 1.6 & 1.0 & 1.5 to 1.8 & - \\
\hline 1 year & 109 & 0.4 & 0.7 & 0.3 to 0.5 & $<0.001$ \\
\hline 5 years & 80 & 0.6 & 0.9 & 0.4 to 0.9 & 0.002 \\
\hline \multicolumn{6}{|c|}{ OP 5: Going on vacation } \\
\hline Baseline & 127 & 1.7 & 1.0 & 1.5 to 1.9 & - \\
\hline 1 year & 110 & 0.4 & 0.7 & 0.3 to 0.5 & $<0.001$ \\
\hline 5 years & 81 & 0.7 & 0.9 & 0.5 to 0.9 & $<0.001$ \\
\hline \multicolumn{6}{|c|}{ OP 6: Trying on and buying clothes } \\
\hline Baseline & 127 & 2.5 & 0.8 & 2.4 to 2.7 & - \\
\hline 1 year & 110 & 0.6 & 0.9 & 0.4 to 0.7 & $<0.001$ \\
\hline 5 years & 81 & 1.0 & 1.0 & 0.8 to 1.2 & $<0.001$ \\
\hline \multicolumn{6}{|c|}{ OP 7: Bathing in public areas (swimming pools, beaches) } \\
\hline Baseline & 127 & 2.5 & 0.9 & 2.3 to 2.6 & - \\
\hline 1 year & 108 & 1.3 & 1.1 & 1.1 to 1.5 & $<0.001$ \\
\hline 5 years & 80 & 1.4 & 1.2 & 1.1 to 1.6 & 0.58 \\
\hline \multicolumn{6}{|c|}{ OP 8: Sexual intercourse, intimate situations } \\
\hline Baseline & 122 & 1.8 & 1.0 & 1.6 to 2.0 & - \\
\hline 1 year & 105 & 0.9 & 1.0 & 0.7 to 1.1 & $<0.001$ \\
\hline 5 years & 79 & 1.0 & 1.1 & 0.8 to 1.3 & 0.22 \\
\hline
\end{tabular}

${ }^{*} \mathrm{P}$ value for change in mean score from previous time point (only based on respondents with data from both time points). The $\mathrm{p}$ values for change from baseline to 5 years are not listed, but are all $<0.001$.

OP, Obesity-Related Problem scale.

remarkable similarities in the pattern of long-term changes in HRQOL across different bariatric surgery procedures (gastric banding, BPDDS, RYGBP and SG), outcome measures and countries. ${ }^{22}$

Several researchers have suggested a dose-response correlation between change in weight and HRQOL. ${ }^{38} 3942$ In the present cohort, weight loss at 5 years after surgery was significantly associated with perceived obesity-specific HRQOL at 5 years. Although most patients reported severe to extreme psychosocial impairment before the operation, their reports after 1 year improved significantly. As weight regain occurred, the proportion of patients reporting severe impairment again increased. The clear association between \%EBMIL and OP indicates that the patients' perception of obesity-specific HRQOL is particularly sensitive to changes in BMI. Similar results were also reported by Karlsson et al for patients with 10-year follow-up after RYGBP. ${ }^{38}$ In addition, Kolotkin $e t$ al reported that percentage excess weight loss at 6 years for RYGBP patients correlated significantly with changes in the IWQOL-Lite total score and PCS, but not MCS. ${ }^{39}$ This close association may, however, not hold true for 


\section{Mental Component Summary (SF-36 MCS)}

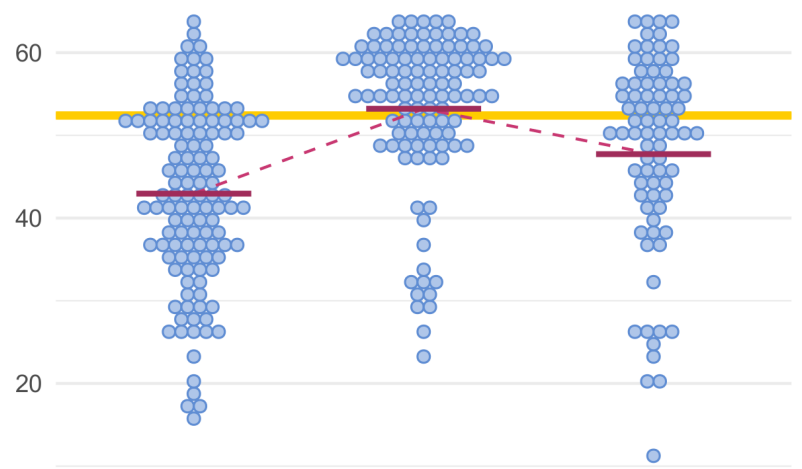

Score

Physical Component Summary (SF-36 PCS)

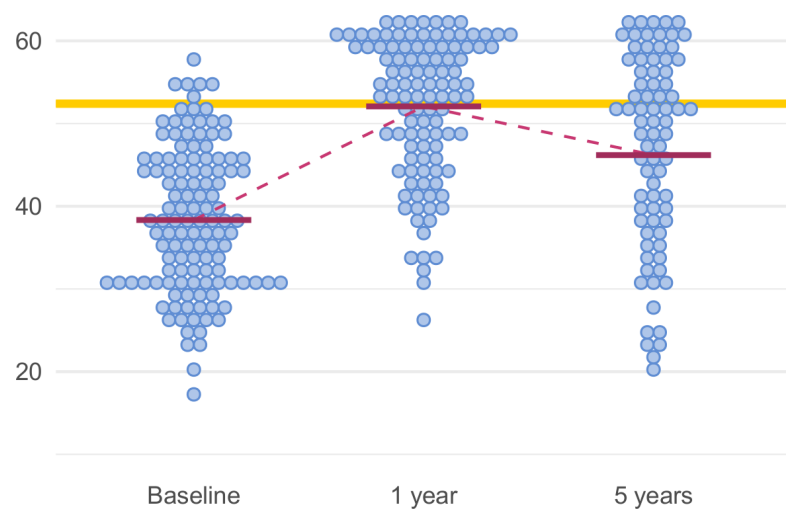

Figure 4 Individual scores for the Short Form 36 Health Survey (SF-36) mental (MCS) and physical (PCS) composite summary scores $\left(n=123^{*}\right)$. Each point corresponds to a single patient. The mean score is marked with horizontal lines. The Norwegian general population norm is marked with a yellow horizontal line. *The number of patients was 123 at baseline, 108 at 1 year and 78 at 5 years, for both PCS and MCS.

all levels of HRQOL, as weight loss at 5 years was significantly associated only with PCS at 5 years and not MCS in our study. Of note, in their study on 5-year outcomes after SG, Charalampakis et al found no such correlations of weight loss and obesity-specific HRQOL, as measured by the MAII questionnaire. ${ }^{9}$ Furthermore, Aasprang et al found no significant correlations between weight loss and MCS and PCS using the SF-36 in their 10-year study after BPDDS. ${ }^{40}$

As the terms HRQOL/overall QOL encompass diverse life domains, one could expect a disparity in the influential power of weight loss on different aspects of life. Along these lines, we report no statistically significant associations between weight loss and broader QOL domains, such as overall QOL. In fact, a recent cross-sectional study on generic and obesity-specific HRQOL 4 years after bariatric surgery, controlling for a number of other variables that may affect QOL, questions the importance of weight loss as the main determinant of improvements in all levels of QOL after surgery. ${ }^{43}$ For a more accurate assessment of the relationship between surgically induced weight loss and
QOL it appears important to differentiate between narrow QOL concepts, related specifically to constraints and concerns associated with changes of weight, and the broader aspects of QOL. The latter may to a larger degree be influenced by other weight-independent factors. Furthermore, despite profound weight loss in a majority of patients we report a noteworthy difference in all aspects of QOL compared with the population norm, suggesting that weight loss alone may be overemphasised in terms of improving patients' lives. In clinical practice, this calls for patient care that centres on other important determinants of QOL than weight loss alone.

\section{Strengths and limitations}

Along with the prospective design and long-term follow-up, the present study reports broad measures of QOL covering overall, generic and disease-specific domains relative to general population scores. To our knowledge this has not been presented after SG before. We cannot rule out other factors that could possibly modify the observed relationships of preoperative weight, weight loss and HRQOL/ overall QOL, such as comorbidities, stressful life events and eating disorders. For example, redundant skin has been reported as an important determinant of poorer psychosocial functioning and generic HRQOL after RYGBP. ${ }^{44}$ No systematic assessment of excessive skin and the degree to which this was a concern for the patients was done in the present cohort.

The proportion of patients lost to follow-up at 5 years represents a limitation. High attrition rates are common in longitudinal bariatric surgery research, comparable to the follow-up rate of $64 \%$ in the present study. ${ }^{845}$ However, there were no significant baseline differences in registered traits comparing patients attending the 5-year follow-up after SG and those missing. By using multiple imputation, any bias caused by missing data is reduced.

\section{Implications and suggestions for future research}

Significant and meaningful long-term improvements in HRQOL/overall QOL after bariatric surgery appear to be consistently reported. Particularly, improved psychosocial functioning as measured by the OP scale may considerably enhance patients' performance in daily life situations. Still, the trend towards weight regain and concurrent decline in HRQOL/overall QOL after initial postoperative improvements remains a concern. This underscores obesity as a refractory chronic condition. Though limited, some knowledge exists about factors that may promote or hinder maintenance of weight loss. ${ }^{46}$ Hence, postoperative support may be of crucial importance to maintain successful short or medium-term outcomes after bariatric surgery. Several studies have emphasised associations between thorough long-term follow-up programmes and endured weight management. ${ }^{4-51}$ As weight control appears particularly important for patients' perceived psychosocial functioning in daily life situations, as reported herein, deciphering 


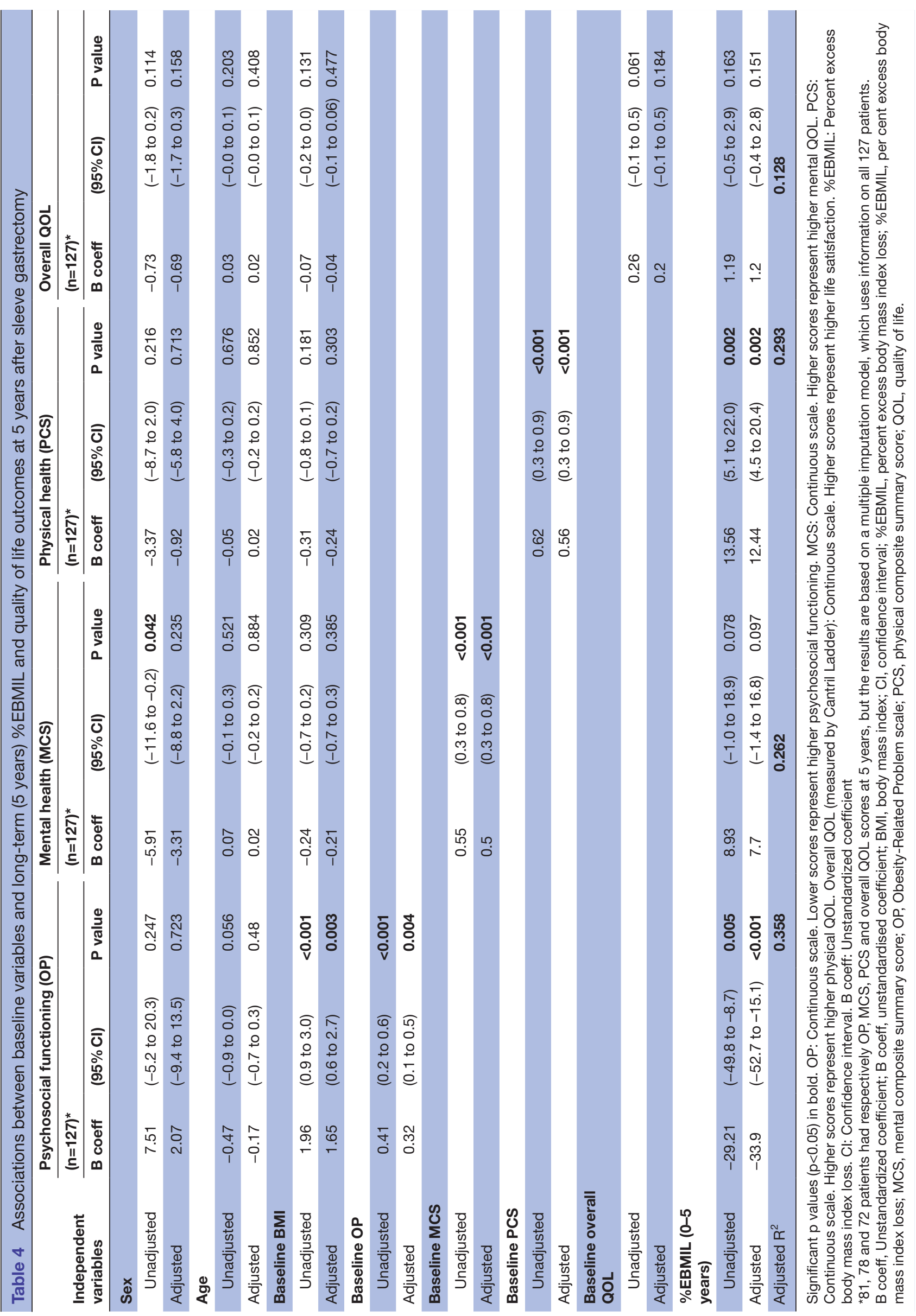

$\stackrel{\square}{3}$

8

寻

음

कั

क

음

항

응

N

ó

जे

온

$\vec{N}$

(D)

苟

오ำ

뭉

方

잉

윽

吾

혹

홍.

욱

ㅇํำ

옹

ㅇㅡㅡ 
components of successful weight maintenance programmes after surgery seems mandatory. Also, our results emphasise that the magnitude of weight loss does not equally influence all aspects of HRQOL and overall QOL. Properly distributed, this knowledge should help bariatric surgery patients to form realistic expectations for their well-being as a result of weight loss alone. Further research should aim to identify coexisting factors that may contribute to impaired QOL before and after bariatric surgery and address the effect of novel interventions to support both long-term weight loss maintenance and HRQOL/overall QOL after surgery.

\section{Author affiliations}

${ }^{1}$ Department of Surgery, Voss Hospital, Haukeland University Hospital, Voss, Norway ${ }^{2}$ Department of Global Public Health and Primary Care, University of Bergen, Bergen, Norway

${ }^{3}$ Faculty of Health and Social Sciences, Western Norway University of Applied Sciences, Førde, Norway

${ }^{4}$ Center of Health Research, Førde Hospital Trust, Førde, Norway

${ }^{5}$ Department of Family Medicine and Community Health, Duke University School of Medicine, Durham, North Carolina, US

${ }^{6}$ Quality of Life Consulting, PLLC, Durham, North Carolina, US

${ }^{7}$ Department of Heart Disease, Haukeland University Hospital, Bergen, Norway

${ }^{8}$ Department of Clinical Science, University of Bergen, Bergen, Norway

${ }^{9}$ Department of Surgery, Haraldsplass Diakonale Sykehus, Bergen, Norway

${ }^{10}$ Scandinavian Obesity Surgery Registry (SOReg-N), The Western Norway Health

Region Authority, Bergen, Norway

${ }^{11}$ Centre for Clinical Research, Haukeland University Hospital, Bergen, Norway

Acknowledgements We thank the participants, patient advisors and other staffs at Førde Central Hospital for their valuable contributions to the study.

Contributors TNF, WV and JRA are responsible for the study concept and design. VW, JRA and AA are responsible for data collection. TNF, JRA and $\mathrm{KOH}$ are responsible for analysis of data. TNF, JRA, RLK, VV, GST, AA, TMN and KOH are responsible for interpretation of data. TNF, JRA, GST and RLK are responsible for initial draft of manuscript. All authors revised the paper critically for important intellectual content and approved the final version of the manuscript. TNF, JRA and $\mathrm{KOH}$ had full access to all of the data (including statistical reports and tables) in the study, and take responsibility for the integrity of the data and the accuracy of the data analysis.

Funding This work was funded by the Western Norway Regional Health Authority (Grant No 912145).

Competing interests None declared.

Patient consent for publication Obtained.

Ethics approval The Regional Committee for Medical and Health Research EthicsWestern Norway approved the study (reference number: 2009/2174).

Provenance and peer review Not commissioned; externally peer reviewed.

Data availability statement Data are available upon reasonable request. Data may be obtained from a third party and are not publicly available. All data relevant to the study are included in the article or uploaded as supplementary information.

Open access This is an open access article distributed in accordance with the Creative Commons Attribution Non Commercial (CC BY-NC 4.0) license, which permits others to distribute, remix, adapt, build upon this work non-commercially, and license their derivative works on different terms, provided the original work is properly cited, appropriate credit is given, any changes made indicated, and the use is non-commercial. See: http://creativecommons.org/licenses/by-nc/4.0/.

\section{REFERENCES}

1. Wee CC, Jones DB, Davis RB, et al. Understanding patients' value of weight loss and expectations for bariatric surgery. Obes Surg 2006;16:496-500.

2. Allegri C, Russo E, Roggi C, et al. Quality of life (QoL) and motivation for treatment: a female issue? Eat Weight Disord 2008;13:e8-13.
3. van Hout GCM, Verschure SKM, van Heck GL. Psychosocial predictors of success following bariatric surgery. Obes Surg 2005;15:552-60.

4. Kolotkin RL, Andersen JR. A systematic review of reviews: exploring the relationship between obesity, weight loss and health-related quality of life. Clin Obes 2017;7:273-89.

5. Welbourn R, Hollyman M, Kinsman R, et al. Bariatric surgery worldwide: baseline demographic description and one-year outcomes from the fourth IFSO global Registry report 2018. Obes Surg 2019;29:782-95.

6. Biter LU, Gadiot RPM, Grotenhuis BA, et al. The sleeve bypass trial: a multicentre randomized controlled trial comparing the long term outcome of laparoscopic sleeve gastrectomy and gastric bypass for morbid obesity in terms of excess BMI loss percentage and quality of life. BMC Obes 2015;2.

7. Salminen P, Helmiö M, Ovaska J, et al. Effect of laparoscopic sleeve gastrectomy vs laparoscopic Roux-en-Y gastric bypass on weight loss at 5 years among patients with morbid obesity. JAMA 2018;319:241-54.

8. Juodeikis Žygimantas, Brimas G. Long-Term results after sleeve gastrectomy: a systematic review. Surg Obes Relat Dis 2017;13:693-9.

9. Charalampakis V, Seretis C, Daskalakis M, et al. The effect of laparoscopic sleeve gastrectomy on quality of life: a prospective cohort study with 5-years follow-up. Surg Obes Relat Dis 2018;14:1652-8.

10. D'Hondt M, Vanneste S, Pottel H, et al. Laparoscopic sleeve gastrectomy as a single-stage procedure for the treatment of morbid obesity and the resulting quality of life, resolution of comorbidities, food tolerance, and 6-year weight loss. Surg Endosc 2011;25:2498-504

11. Felsenreich DM, Prager G, Kefurt R, et al. Quality of life 10 years after sleeve gastrectomy: a multicenter study. Obes Facts 2019;12:157-66.

12. Flølo TN, Andersen JR, Kolotkin RL, et al. Five-Year outcomes after vertical sleeve gastrectomy for severe obesity: a prospective cohort study. Obes Surg 2017;27:1944-51.

13. Cramer JA, Spilker B. Quality of life and pharmacoeconomics an introduction. Philadelphia, PA: Wolters Kluwer/Lippincott Williams \& Wilkins, 1998.

14. Våge V, Sande VA, Mellgren G, et al. Changes in obesity-related diseases and biochemical variables after laparoscopic sleeve gastrectomy: a two-year follow-up study. BMC Surg 2014;14:8.

15. Brethauer SA, Kim J, El Chaar M, et al. Standardized outcomes reporting in metabolic and bariatric surgery. Obes Surg 2015;25:587-606.

16. Lauti M, Kularatna M, Hill AG, et al. Weight regain following sleeve Gastrectomy - a systematic review. Obes Surg 2016;26:1326-34.

17. Mann JP, Jakes AD, Hayden JD, et al. Systematic review of definitions of failure in revisional bariatric surgery. Obes Surg 2015;25:571-4.

18. Lager CJ, Esfandiari NH, Subauste AR, et al. Milestone weight loss goals (weight normalization and remission of obesity) after gastric bypass surgery: long-term results from the University of Michigan. Obes Surg 2017;27:1659-66.

19. Karlsson J, Taft C, Sjöström L, et al. Psychosocial functioning in the obese before and after weight reduction: construct validity and responsiveness of the obesity-related problems scale. Int $J$ Obes 2003;27:617-30.

20. Aasprang A, Andersen JR, Våge V, et al. Psychosocial functioning before and after surgical treatment for morbid obesity: reliability and validation of the Norwegian version of obesity-related problem scale. PeerJ 2015;3:e1275.

21. Kolotkin RL, Meter K, Williams GR. Quality of life and obesity. Obesity Reviews 2001;2:219-29.

22. Andersen JR, Aasprang A, Karlsen T-I, et al. Health-Related quality of life after bariatric surgery: a systematic review of prospective longterm studies. Surg Obes Relat Dis 2015;11:466-73.

23. Ware JE. SF-36 health survey update. Spine 2000;25:3130-9.

24. Karlsen T-I, Tveitå EK, Natvig GK, et al. Validity of the SF-36 in patients with morbid obesity. Obes Facts 2011;4:346-51.

25. Cantril H. The pattern of human concerns. New Brunswick. New Jersey: Reuters University Press, 1965: 3-29.

26. Levin KA, Currie C. Reliability and validity of an adapted version of the Cantril ladder for use with adolescent samples. Soc Indic Res 2014;119:1047-63.

27. Larsson I, Bertéus Forslund H, Lindroos AK, et al. Body composition in the SOS (Swedish obese subjects) reference study. Int J Obes 2004;28:1317-24.

28. Hougen H, Gløboden MA. Samordnet levekårsundersøkelse 2005: Statistisk Sentralbyrå, Oslo 2005. 
29. Statistics Norway: Levekårsundersøkelsen EU-SILC. Oslo, Norway Statistisk sentralbyrå (SSB); 2017.

30. Aasprang A, Andersen JR, Våge V, et al. Five-Year changes in healthrelated quality of life after biliopancreatic diversion with duodenal switch. Obes Surg 2013;23:1662-8.

31. Pinheiro JBD, DebRoy S, Sarkar D. nlme: linear and nonlinear mixed effects models. Available: https://CRAN.R-project.org/package= nlme>2018

32. Harrell FE. Regression modelling strategies. Available: https://CRAN. R-project.org/package $=$ rms2019

33. Hjermstad MJ, Fayers PM, Bjordal K, et al. Using reference data on quality of life--the importance of adjusting for age and gender, exemplified by the EORTC QLQ-C30 (+3). Eur J Cancer 1998;34:1381-9.

34. Cohen J. Statistical power analysis for the behavioral sciences. 2nd ed. Hillsdale, NJ: Lawrence Erlbaum Associates, 1988: xv 474.

35. Fuller CD, Braden CJ, Thomas CR. Quality of life: from a tower of Babel toward a unified voice. Int J Radiat Oncol Biol Phys 2004;58:1334-5.

36. $R$ : a language and environment for statistical computing URL: $R$ foundation for statistical computing, Vienna, Austria, 2018. Available: https://www.R-project.org/

37. von Elm E, Altman DG, Egger M, et al. The strengthening the reporting of observational studies in epidemiology (STROBE) statement: guidelines for reporting observational studies. J Clin Epidemiol 2008;61:344-9.

38. Karlsson J, Taft C, Rydén A, et al. Ten-Year trends in healthrelated quality of life after surgical and conventional treatment for severe obesity: the SOS intervention study. Int $J$ Obes 2007;31:1248-61.

39. Kolotkin RL, Davidson LE, Crosby RD, et al. Six-Year changes in health-related quality of life in gastric bypass patients versus obese comparison groups. Surg Obes Relat Dis 2012;8:625-33.

40. Aasprang A, Andersen JR, Våge V, et al. Ten-Year changes in healthrelated quality of life after biliopancreatic diversion with duodenal switch. Surg Obes Relat Dis 2016;12:1594-600.
41. Kolotkin RL, Kim J, Davidson LE, et al. 12-Year trajectory of healthrelated quality of life in gastric bypass patients versus comparison groups. Surg Obes Relat Dis 2018;14:1359-65.

42. Strain GW, Kolotkin RL, Dakin GF, et al. The effects of weight loss after bariatric surgery on health-related quality of life and depression. Nutr Diabetes 2014;4:e132.

43. Dagsland V, Andenæs R, Karlsen T-I. Generic Health-Related Quality of Life May Not Be Associated with Weight Loss 4 Years After Bariatric Surgery: a Cross-Sectional Study. Obes Surg 2018;28:3142-50.

44. Marek RJ, Steffen KJ, Flum DR, et al. Psychosocial functioning and quality of life in patients with loose redundant skin 4 to 5 years after bariatric surgery. Surg Obes Relat Dis 2018;14:1740-7.

45. Arterburn D, Wellman R, Emiliano A, et al. Comparative effectiveness and safety of bariatric procedures for weight loss. Ann Intern Med 2018;169:741-50.

46. Flølo TN, Tell GS, Kolotkin RL, et al. Eating self-efficacy as predictor of long-term weight loss and obesity-specific quality of life after sleeve gastrectomy: a prospective cohort study. Surg Obes Relat Dis 2019;15:161-7.

47. Neville A. The difficulty of predicting long-term weight loss after gastric bypass. JAMA Surg 2016;151:1062-3.

48. Herring LY, Stevinson $C$, Carter $P$, et al. The effects of supervised exercise training 12-24 months after bariatric surgery on physical function and body composition: a randomised controlled trial. Int $J$ Obes 2017;41:909-16.

49. Kaiser KA, Franks SF, Smith AB. Positive relationship between support group attendance and one-year postoperative weight loss in gastric banding patients. Surg Obes Relat Dis 2011;7:89-93.

50. Livhits M, Mercado C, Yermilov I, et al. Is social support associated with greater weight loss after bariatric surgery?: a systematic review. Obes Rev 2011;12:142-8.

51. Martins MP, Abreu-Rodrigues M, Souza JR. The use of the Internet by the patient after bariatric surgery: contributions and obstacles for the follow-up of multidisciplinary monitoring. $A B C D$, arq. bras. cir. dig. 2015;28(suppl 1):46-51. 